\title{
Custos de técnicas sustentáveis e aplicáveis em recuperação de áreas de pastagens
}

\section{Patrícia Conceição da Silva ${ }^{1}$, Raisa Gomes Diniz ${ }^{2}$, Marco Antônio Alves Ferreira ${ }^{2}$, Duílio Júlio Oliveira $\operatorname{Santos}^{3}$ e Gilmar Oliveira Santos ${ }^{1}$,*}

${ }^{1}$ Universidade de Rio Verde (UniRV). Fazenda Fontes do Saber. Caixa Postal 104. Rio Verde-GO, Brasil (CEP 75901-970).*E-mail: gilmar@unirv.edu.br.

${ }^{2}$ Programa de Pós-Graduação em Mestrado em Produção Vegetal. Universidade de Rio Verde (UniRV). Fazenda Fontes do Saber. Caixa Postal 104. Rio Verde-G0, Brasil (CEP 75901-970).

${ }^{3}$ Universidade Federal de Uberlândia. Rua 20, no 1600. Bairro Tupã. Ituiutaba-MG, Brasil (CEP 38304-402).

Resumo. Um solo sem nutrientes suficiente para produzir uma boa pastagem pode gerar grandes prejuízos econômicos e ambientais para o produtor, como erosões, assoreamento dos rios, compactação do solo, perda de solo fértil e perda no preço do animal. Esta pesquisa apresenta três técnicas que podem ser utilizadas na recuperação de áreas de pastagem degradadas, o plantio de melancia, o sistema de integração lavoura-pecuáriafloresta (IPLF) e o sistema silvipastoril. Comparou-se com a técnica convencional de plantio de pastagem, no qual se considerou aspectos econômicos e ambientais. 0 plantio da melancia apresentou valor de custo de quase $60 \%$ superior em relação ao método convencional. 0 sistema ILPF, apresentou o maior custo de produção, atingindo um valor de aproximadamente $78 \%$ a mais que a técnica convencional. A implantação do sistema silvipastoril possui custo de $\mathrm{R} \$ 4.135,74$ por hectare para a sua implantação correspondendo a $56 \%$ a mais que o custo necessário para a implantação da técnica convencional. 0 sistema convencional apresenta menor custo de implantação, porém poderá trazer vários prejuízos ao solo e à pastagem. Apesar de todas as técnicas de recuperação nãoconvencional apresentarem custos superiores à técnica convencional, elas trarão retorno econômicos de curto a longo prazo, além de trazerem vários benefícios ao produtor e ao meio ambiente, como a cobertura do solo e aumento dos nutrientes necessários para que seja fértil.

Palavras-chave: Integração lavoura-pecuária; Integração lavoura-pecuária e floresta; Recuperação de áreas degradadas.

Abstract. Costs of sustainable techniques and support in the recovery of pasture areas. A soil without enough nutrients to produce a good pasture can generate great economic and
Recebido

$15 / 04 / 2019$

Aceito

$15 / 11 / 2019$

Disponível on line

19/11/2019

Publicado

$31 / 12 / 2019$

Acesso aberto

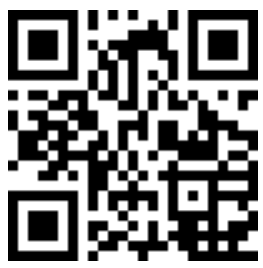

ORCID

(1) 0000-0002-8595-2515 Patrícia Conceição da Silva

(D) 0000-0003-4950-7382

Raisa Gomes Diniz

D) 0000-0002-1880-1725

Marco Antônio Alves Ferreira 
environmental damages to the producer, such as erosion, silting of rivers, soil compaction, loss of fertile soil and loss of animal price. This research presents three techniques that can be used in the recovery of grazing areas degraded, watermelon planting, the integrated crop-livestock-forest system (ILPF), and the silvopastoral system. It was compared with the conventional technique of pasture planting, in which economic and environmental aspects were considered. The planting of the watermelon had cost value of almost $60 \%$ higher than the conventional method. The ILPF system presented the highest cost of production, reaching a value of approximately $78 \%$ more than the conventional technique. The implementation of the silvopastoral system has a cost of $\mathrm{R} \$ 4,135.74$ per hectare for its implementation, corresponding to $56 \%$ more than the cost required for the implementation of the conventional technique. The conventional system presents a lower cost of implantation, but can bring several damages to the soil and the pasture. Despite all the unconventional recovery techniques, they present higher costs than conventional techniques, they will bring economic returns from the short to long term, besides bringing various benefits to the producer and the environment, such as the soil cover and the increase of the necessary nutrients to be fertile.

Keywords: Crop-livestock integration; Crop-livestock-forest integration; Degraded area recovery.

\section{Introdução}

A utilização de áreas para a criação de bovinos tem sido altamente utilizada no Brasil. Mundialmente, o Brasil é o maior produtor e o segundo maior consumidor de carne bovina no mundo (USDA, 2018).

Para Silva et al. (2017),em regiões tropicais, o pasto representa 0 recurso nutricional mais importante na produção de ruminantes, uma vez que a criação desses é basicamente dependente do consumo de forragem oriunda das pastagens, principalmente por ser uma forma economicamente viável, porém a parte econômica muitas vezes isola a parte sustentável e o manejo dessas áreas é deixado em segundo plano.

A degradação das pastagens, deve-se pela exploração por décadas da fertilidade natural dos solos, em áreas desmatadas para a implantação de forrageiras com alto potencial produtivo e consequentemente de alta exigência nutricional, além da exaustão de
(D) 0000-0002-3538-736X

Duílio Júlio Oliveira Santos

D) 0000-0002-4497-6107 Gilmar Oliveira Santos nutrientes do solo, propicia a emergência de plantas daninhas e redução do potencial produtivo das forrageiras, devido a competição (Silva et al., 2018).

Para Pinheiro et al. (2018), a remoção da cobertura vegetal, promove a degradação e produz consequências sobre os diferentes componentes ambientais, como perda total ou parcial do solo devido a erosões hídricas, assoreamento, eutrofização dos cursos d'água.

A utilização de técnicas para o manejo do solo em áreas que são utilizadas para pastagens trazem diversos benefícios tanto para o animal e produtor, quanto para o meio ambiente. Oliveira et al. (2015), citam alguns desses benefícios, com maior cobertura no solo e consequentemente controle de erosões, aumento da fertilidade das plantas; rentabilidade na produção e melhor desempenho animal.

A recuperação da pastagem aperfeiçoa o aproveitamento da área, recupera as propriedades químicas, 
físicas e biológicas do solo e viabiliza a produção de proteína animal, devido ao aumento da capacidade de suporte, não obstante, impede novos desmatamentos preservando a fauna e a flora (Carvalho et al., 2017).

Este trabalho foi motivado pela necessidade de se apresentar técnicas viáveis e aplicáveis para a recuperação e conservação do solo de pastagens degradadas, visto que poderá auxiliar os produtores a conservar sua propriedade, já que a região de estudo possui muitas áreas direcionadas para a pecuária, e que essa atividade pode gerar vários danos ambientais.

Portanto, este trabalho tem como objetivo realizar o levantamento de custos de técnicas sustentáveis e aplicáveis para a recuperação de áreas de pastagens no município de Rio Verde, Goiás.

\section{Material e métodos}

\section{estudo \\ Caracterização da área de}

0 presente estudo foi realizado no Município de Rio Verde, Microrregião Sudoeste do Estado de Goiás, CentroOeste brasileiro, situada a $739 \mathrm{~m}$ de altitude, na coordenada geográfica de referência $17^{\circ} 47^{\prime} 50^{\prime \prime} \mathrm{S}$ e $50^{\circ} 54^{\prime} 0^{\prime \prime} \mathrm{O}$ e ocupa uma área de $8.415,40 \mathrm{~km}^{2}$.

0 clima da região apresenta duas estações bem definidas, uma seca (de maio a outubro) e outra chuvosa (novembro a abril).

A topografia da região é plana a suavemente ondulada, com pendentes longas e declividades próximas de 3\%. Seu solo é do tipo Latossolo Vermelho Escuro com texturas argilosa e arenoargilosa (Ralisch et al., 2008).

\section{Técnicas de recuperação de áreas degradadas \\ Como forma de propostas para} assegurar que não ocorra degradação das áreas de pastagens, foram sugeridos três métodos de recuperação, onde foi avaliado o valor de retorno de investimento em relação a técnica convencional.

As técnicas propostas foram o plantio de melancia, a integração lavoura-pecuária e floresta (IPLF) e o sistema silvipastoril (SSP).

\section{0 plantio de melancia}

A técnica do plantio de melancia ocorre através do plantio de sementes de melancia no período de seca, portanto irrigada, período em que o pasto é pouco eficiente como fonte de alimento para os animais ruminantes. Nesse período a pastagem estará sendo recuperada pelos benefícios que a técnica irá trazer para o solo.

Para o plantio da melancia, o ideal é plantar no mês em que há menor ocorrência de chuvas, para evitar assim a proliferação de doenças. Sendo assim, os meses melhor indicados para o plantio-colheita são de maio a outubro, havendo a necessidade de irrigação.

Segundo Souza (2008) é necessário que se faça a calagem para que $\mathrm{o} \mathrm{pH}$ do solo seja corrigido, recomenda-se entre $250 \mathrm{~g}$ e $400 \mathrm{~g}$ de calcário dolomítico por cova ou 1.660 $\mathrm{kg} / \mathrm{ha}$. Para o cálculo utiliza-se a quantidade de $1.660 \mathrm{~kg} / \mathrm{ha}$.

Para a adubação, Souza (2008) indica uma quantidade de $100 \mathrm{~kg} / \mathrm{ha}$ de adubo nitrogenado, podendo ser usado, por exemplo, a ureia, juntamente com o cloreto de potássio, na quantidade de $30 \mathrm{~kg} / \mathrm{ha}$ a $120 \mathrm{~kg} / \mathrm{ha}$ dividido em três aplicações, na fundação e após 25 e 40 dias do plantio. Para o superfostato simples devem ser aplicadas doses de 30 $\mathrm{kg} / \mathrm{ha}$ a $120 \mathrm{~kg} / \mathrm{ha}$ apenas na fundação.

Para Yuri et al. (2013), o plantio se inicia com a semeadura direta de uma ou duas sementes por cova, em espaçamento de $2,5 \mathrm{~m}$ a 3,0 $\mathrm{m}$ entre linhas por $0,6 \mathrm{~m}$ entre plantas, e profundidade da semeadura, que não ultrapasse $3,0 \mathrm{~cm}$. No trabalho em questão utilizou-se espaçamento de $0,6 \mathrm{~m} \times 2,5 \mathrm{~m}$ e de acordo com Reis et al. (2010) utiliza-se 
geralmente em semeadura direta, uma média de $0,7 \mathrm{~kg}$ a $1 \mathrm{~kg}$ de sementes por hectare.

A demanda hídrica da melancia pode variar de acordo com a qualidade e tipo de semente usada e também da condição edafoclimática da região, podendo consumir de $300 \mathrm{~mm}$ a $550 \mathrm{~mm}$ por ciclo de produção (Reis et al., 2010), na região estudada não é cobrado o uso da água, portanto não será mencionado o valor nos resultados.

A colheita do fruto deverá ser iniciada entre 35 e 45 dias após a abertura das flores, o que corresponde ao período entre 65 a 75 dias após o plantio, dependendo das condições climáticas da região de plantio, e pode ser feita de forma manual (Yuri, 2013).

Após a colheita do fruto foi a folhagem foi deixada no local para compôs a cobertura do solo até que ocorra as primeiras chuvas, assim no período de no máximo 45 dias a pastagem brotara naturalmente $\mathrm{e}$ fornecerá alimento para o gado.

\section{Integração lavoura-pecuária- floresta (ILPF)}

0 sistema funciona basicamente com o plantio, durante o verão de árvores e culturas agrícolas anuais (arroz, feijão, milho, soja ou sorgo), associado a espécies forrageiras.

As árvores devem ser plantadas primeiramente, pois as suas linhas vão orientar o plantio da cultura anual, o espaçamento do plantio deverá ser observado de acordo com a finalidade do sistema e da espécie arbórea escolhida (Tomaz et al., 2017). Neste trabalho fio utilizado o eucalipto (Eucalyptus).

Bonini (2016) cita que para área em que as mudas serão plantadas deverá haver a correção do solo com $350 \mathrm{~kg} / \mathrm{ha}$ de superfosfato simples e adubação de cobertura de com 100 g por planta da formulação NPK 20-00-20.

Para Tomaz et al. (2017) é necessário que haja um espaçamento de $1 \mathrm{~m}$ de cada lado das linhas das árvores, para não haver competição e esse espaço deverá ser limpo. Os espaçamentos mais utilizados compreendem a distancia de $30 \mathrm{~m}$ entre os renques e uma distância de $3,5 \mathrm{~m} \times 3,0 \mathrm{~m}$ entre plantas e em linhas triplas (Diel et al., 2014).

Diel et al. (2014) citam que para o primeiro ano do sistema, para a área que primeiramente será utilizada para plantio de cultura anual, deverá ser utilizados para a correção do solo, $400 \mathrm{~kg} / \mathrm{ha}$ de NPK 04-30-16.

Nogueira et al. (2016) utilizou-se como cultura anual na safra a soja, cultivar BRSGO 8660 (RR) que foi semeada em linhas em uma quantidade de $25 \mathrm{~kg}$ de sementes porha.

De acordo com Diel et al. (2014), a cultura da soja necessita de $400 \mathrm{~kg} / \mathrm{ha}$ de NPK 00-20-20 e adubações de cobertura. Vilela et al. (2011) salienta que essa técnica rompera o ciclo de proliferação de doenças, pragas e também a proliferação de insetos oque resultará na redução da quantidade de herbicidas utilizados para manejo.

A partir do terceiro ano do sistema a cultura anual poderá ser cultivada associada a uma espécie de forrageira, que servirá como forma de pastagem para a introdução de animais após a colheita do cereal (Rangel et al., 2010).

Na condição de pastejo utiliza-se 5 a $10 \mathrm{~kg}$ de semente de braquiária por hectare. A espécie mais utilizada para forragem são Brachiaria brizantha, Brachiaria decumbens ou Brachiaria ruziziensis. Para fator de cálculo utilizouse a quantidade de $7 \mathrm{~kg} / \mathrm{h}$ a de semente de Brachiaria decumbens.

A introdução da espécie forrageira só terá início após o segundo ano da implantação do sistema, quando a introdução dos animais para pastejo não causar prejuízo para a cultura das árvores.

\section{Sistemas silvipastoris}

O Sistema Silvipastoril (SSP) é a combinação intencional de árvores, pastagem e gado numa mesma área ao mesmo tempo e manejados de forma 
integrada. A influência que as árvores terão sobre a área é uma combinação de sombra e adição de nutrientes ao solo, consequentemente maior crescimento das gramíneas e melhor qualidade, outra importante vantagem é que auxiliará no controle de erosões. (Araújo et al., 2011)

Para o preparo do solo foi necessário a aração e uma gradagem para limpeza do pasto e controle de espécie invasoras, posteriormente é feito a abertura das covas de $0,3 \times 0,3 \times 0,3 \mathrm{~m}$. A adubação foi feita na cova com $100 \mathrm{~g}$ de NPK (06-30-06), e também após o plantio (Keller et al., 2009).

Neste sistema utiliza-se o plantio árvores dispersas na pastagem levando em consideração estudos, esse método trará aumento da fertilidade do solo pela incorporação de nutrientes, sombra e proteção, além de fornecer em longo prazo madeira de melhor qualidade e rendimento. Moreira et al. (2009) recomenda o uso de em média de 115 árvores por hectare para que se tenha uma boa densidade arbórea.

Nesta pesquisa, foi utilizada a espécie Zeyheria tuberculosa, popularmente conhecida como ipê-felpudo ou bolsa-de-pastor.

Na etapa do cultivo da pastagem Vilela et al. (1998) recomenda que para o uso da Brachiaria decumbens utilizar $70 \mathrm{~kg}$ de $\mathrm{P}_{2} \mathrm{O}_{5} /$ ha já que não é um espécie exigente e $20 \mathrm{~kg}$ de $\mathrm{K}_{2} \mathrm{O} /$ ha para solo com um teor médio de potássio já existente.

\section{Técnica convencional}

Consiste em se fazer a análise do solo, para determinar sua fertilidade. De acordo com os resultados obtidos é realizada a preparação do solo. 0 objetivo desta prática é o de aproveitar a adubação residual empregada no pasto anual para recuperar a pastagem já existente no solo ou introduzir uma espécie com menor custo.

É necessário que se faça a retirada de vegetação indesejadas e plantas daninhas e em seguida a análise do solo para determinar os valores nutricionais do mesmo. É necessário também o uso de gradeador para a modificação da estrutura do solo.

Para retirada de plantas daninhas faz-se uma aração e duas gradagem sete dias antes da semeadura, e para o controle de posteriores vegetações indesejáveis que venham aparecer podese utilizar o herbicida Gramoxone 200 $(0,5 \mathrm{~kg} / \mathrm{ha})$ logo após a semeadura (Jakelaitis et al., 2004).

Para Rheinheimer et al. (2000), a quantidade de calcário necessário para se fazer a calagem de uma área de pastagem é de $17 \mathrm{t} / \mathrm{ha}$ para que o $\mathrm{pH}$ fique próximo de 6 e o modo de aplicação de ser o mais homogêneo possível.

Utiliza-se 5 a $10 \mathrm{~kg}$ de semente de braquiária por hectare com valor cultural (VC) igual ou superior a 30\%, a espécie mais utilizada para forragem são Brachiaria brizantha, Brachiaria decumbens ou Brachiaria ruziziensis. Neste estudo, foi simulado as espécies Brachiaria decumbens na quantidade de $8 \mathrm{~kg} /$ ha de semente.

Depois de o solo preparado o plantio deverá ser feito juntamente com a adubação em espaçamento de linhas de até $0,8 \mathrm{~m}$, poderá ser feito a lanço também desde que a semente seja coberta com uma fina camada de solo (Nepomuceno, 2016).

Vilela et al. (1998) recomenda que para o uso da Brachiaria decumbens utiliza-se $70 \mathrm{~kg}$ de $\mathrm{P}_{2} \mathrm{O}_{5} /$ ha já que não é um espécie exigente e $20 \mathrm{~kg}$ de $\mathrm{K}_{2} \mathrm{O} /$ há para solo com um teor médio de potássio já existente.

\section{Resultados e discussão}

Levando em consideração os valores de mercado, foi realizado o levantamento de custos em cada forma de manejo do solo, e condução da cultura (Tabela 1).

0 plantio da melancia apresentou valor de custo de quase $60 \%$ superior em relação ao método convencional, mesmo considerando que a pastagem irá 
rebrotar após a colheita da melancia e não haverá necessidade de se fazer uma nova semeadura.

O sistema ILPF, apresentou 0 maior custo de produção, atingindo um valor de aproximadamente $80 \%$ a mais que a técnica convencional, isso devido ao valor da mão-de-obra elevada para o plantio das mudas de eucalipto.
A implantação do sistema silvipastoril possui custo de $\mathrm{R} \$ 4.135,74$ por hectare para a sua implantação correspondendo a $56 \%$ a mais que o custo necessário para a implantação da técnica convencional, o custo desse sistema se torna elevado devido a mão de obra para plantio da muda do ipêfelpudo.

Tabela 1. Custos (R\$) de cada forma de manejo do solo proposto no trabalho.

\begin{tabular}{lcccc}
\hline Procedimentos & $\begin{array}{c}\text { Plantio de } \\
\text { melancia }\end{array}$ & ILPF & Silvipastoris & $\begin{array}{c}\text { Convencion } \\
\text { al }\end{array}$ \\
\hline Análise do solo & - & - & - & 30,00 \\
Adubo (kg/ha) & 237,80 & $1.291,17$ & 155,70 & 147,40 \\
Maquinário (horas)* & 143,00 & 263,00 & 40,00 & 163,20 \\
Mão de obra (homens/5 dia ha)** & $3.200,00$ & $6.400,00$ & $3.200,00$ & - \\
Sementes (kg/ha) & 714,97 & 110,22 & 85,69 & 85,68 \\
Mudas (ha) & - & 714,00 & 654,35 & - \\
Correção do pH & 132,80 & - & - & $1.360,00$ \\
Herbicida (kg/ha) & - & - & - & 9,00 \\
\hline Total & $4.428,57$ & $8.778,39$ & $4.135,74$ & $1.795,28$ \\
\hline
\end{tabular}

*O maquinário está incluso operador e combustível.

** Mão de obra para colheita do fruto, plantio de mudas e desrrame.

Apesar do Sistema ILPF apresentar o maior valor para implantação, haverá ainda dois tipos de renda nessa técnica: a produção da madeira do eucalipto podendo gerar uma renda de aproximadamente $\mathrm{R} \$ 1.400,00 \mathrm{~m}^{3} / \mathrm{ha}$ por ano (médio prazo) e da semente da cultura anual com uma renda de aproximadamente $5.648,16 \mathrm{~kg} / \mathrm{ha}$ por ano (curto prazo), que dará uma renda total da técnica por hectare de aproximadamente $\mathrm{R} \$ 7.048,16$ por ano (Tabela 2). Por tanto, se terá um custo para a produção de aproximadamente $\mathrm{R} \$ 1.730,23$ por hectare já que o valor de renda amenizará o valor de custo.

Pode-se ainda destacar como benefício desta técnica 0 conforto térmico que os animais terão a partir das árvores plantadas, ajudando na melhora da produção animal e aumentando a renda que produtor terá com os animais.
Como fator ambiental pode-se destacar o fato de ocorrer a cobertura do solo em todos os processos do sistema, evitando que ocorra prejuízos e degradação do mesmo, como erosão e perda de solo fértil. Nesta técnica temos como ponto negativo o uso em todas as etapas de correção e adubação do solo com produtos químicos.

Para a técnica do plantio da melancia, se tem como forma de rentabilidade o fruto, que poderá gerar uma renda por hectare de aproximadamente R\$ 15.750,00 a cada ciclo (média de 75 dias por ciclo) (Tabela 2), obtendo lucro $\mathrm{R} \$ 10.321,43$ por hectare a cada ciclo (curto prazo).

0 manejo ainda beneficia a redução no consumo de agroquímicos para a produção forrageira que na maioria das vezes é necessário para realizar a correção do solo, devido ao 
plantio da melancia trazer esses benefícios, além de não se ter despesas com a semeadura, pois a cobertura que o plantio do fruto deixará no solo preservará a umidade de matéria orgânica já presente no local, dando a maior possibilidade de a pastagem rebrotar com maior valor nutricional e eficiência, o que propiciará maior benefício para criação animal que se alimentará, consequentemente maior valor de venda do animal e/ou menor tempo de confinamento.

No uso do plantio da melancia como forma de manejo do solo de pastagens como fator sustentável, notase o fato de o solo ficar coberto pela matéria seca (folhas) da melancia após a colheita do fruto, impedindo assim que ocorra erosão no solo, perda de fertilidade e matéria orgânica, e consequentemente assegurando a ocorrência de assoreamento nos mananciais, além da menor utilização de agroquímicos para a correção do solo, como mencionado anteriormente.

Portanto, esta técnica poderá trazer uma renda no valor aproximado de $\mathrm{R} \$ 14.580,00$ ao produtor durante o ano, e considerando o ciclo da Zeyheria tuberculosa de 20 anos poderá ter um retorno de aproximadamente $\mathrm{R} \$$ 291.600,00, tendo uma forma de poupança (longo prazo) nessa técnica (Tabela 2). Pode-se destacar também que o produtor terá que investir um valor de $\mathrm{R}$ \$ 4.135,74 no início da implantação da técnica, obtendo o lucro após os 20 anos com a colheita da madeira, no valor de $\mathrm{R} \$ 287.464,26$.

Tabela 2. Renda de cada forma de manejo proposta nesse trabalho.

\begin{tabular}{lcccc}
\hline Técnica & Quantidade & Descrição & $\begin{array}{c}\text { Valor } \\
\text { unitário } \\
\text { (R\$) }\end{array}$ & $\begin{array}{c}\text { Valor total } \\
\text { (R\$) }\end{array}$ \\
\hline Plantio de melancia & $35.000 \mathrm{~kg} /$ ha ciclo & Melancia & 0,45 & $15.750,00$ \\
ILPF & $35 \mathrm{~m}^{3} / \mathrm{ha}$ ano & Madeira de eucalipto & 35,00 & $1.400,00$ \\
& $3.362 \mathrm{~kg} / \mathrm{ha}$ ano & Venda da soja & 1,68 & $5.648,16$ \\
Silvipastoril & $24 \mathrm{~m}^{3} / \mathrm{ha}$ ano & Madeira de ipê serrado & 607,50 & $14.580,00$ \\
Convencional & $480 \mathrm{~m}^{3} / \mathrm{ha} 20$ anos & Madeira de ipê serrado & 607,50 & $291.600,00$ \\
\hline
\end{tabular}

Como fator benéfico para este sistema, que se utiliza da Zeyheria tuberculosa para fazer o manejo do solo e ao mesmo tempo auxiliar no bem-estar dos animais, não foi necessário o uso tão intenso e constante de agroquímicos, devido à cultura ter boa adaptação ao solo do cerrado e ter boa resistência em épocas de seca. Neste caso, o fator condicionante seria o solo, que não ficou coberto na época da seca, porque a gramínea seca e deixa o solo exposto, mas há de se notar que o ipê-felpudo traz uma cobertura nos locais plantados, e diminui o efeito splash causado pelas gotas da chuva, podendo evitar que ocorra erosão laminar nas áreas plantadas, diminuindo a compactação do solo.

0 menor valor de custo para implantação é encontrado no sistema convencional devido ao processo ser simples, a despesa maior seria com a correção do solo para a realização da semeadura, porém poucos produtores realizam essa etapa por gerar custos e a renda ser em longo prazo, o que faz com que ocorram prejuízos ao solo e a pastagem por falta de nutrientes e técnicas que garantam a sustentabilidade do processo. Porém este é o método mais utilizado entre os produtores, devido ao 
fator da simplicidade e baixo custo de implantação.

A renda encontrada no sistema convencional se dará através da venda do gado, podendo ter em média $\mathrm{R} \$ 17.466,00 \mathrm{UA} / \mathrm{ha}$. 0 fator crítico ocorre na época de estiagem, em que a pastagem e os animais sofrem pela falta de água, fazendo com que a gramínea se torne escassa e sem nutrientes afetando assim os animais e consequentemente deixando o solo mais exposto, permitindo que degradação como erosões, perda de nutriente e matéria orgânica ocorra com maior intensidade e diminuindo a renda do produtor.

A técnica do plantio de melancia trará uma renda ao produtor em um tempo de aproximadamente 75 dias e após a área ficará a disposição do produtor para introduzir o gado, está técnica poderá ser utilizada por aqueles que pretendem obter uma renda a curto prazo e deixar toda a área a disposição do gado.

Já com a técnica de ILPF, o produtor estará se beneficiando com a produção do grão da cultura anual a médio prazo e com a produção da madeira retorno a longo prazo e ainda poderá, no final do ciclo da cultura anual, utilizar a área como pastagem.

O Sistema Silvipastoril trará uma renda ao produtor a longo prazo devido ao cultivo da madeira do ipê- felpudo, portanto, utilizará desta técnica aqueles que desejarem obter uma poupança com lucro a partir de 20 anos e utilizar a área para pastagem durante todo o ano.

\section{Conclusão}

Todas as técnicas de recuperação não-convencional apresentaram custo superior à técnica convencional, porém, há um retorno econômicos gerado pelas técnicas, além da renda com a produção de gado, diferente do método convencional que terá renda apenas com o gado.

Com o cultivo da melancia, o retorno financeiro será em curto prazo, diferente do sistema ILPF, que pode haver retorno em curto e médio prazo ou ainda o sistema silvipastoril, que trará renda em longo prazo.

0 uso das técnicas "não-convencionais" e o manejo correto das técnicas e do solo poderão trazer vários benefícios ao produtor e ao meio ambiente, como a cobertura do solo evitando que degradações ocorram e trazendo nutrientes necessários para que seja fértil, o que afetará de forma positiva, diferente do sistema convencional que muitos produtores não aderem a ideia devido ao elevado custo e o retorno podendo varias de curto alongo prazo.

\section{Conflito de interesses}

Os autores declaram não haver conflito de interesses.

\section{Referências}

Araújo, R. P.; Almeida, J. C. C.; Deminicis, B. B.; Araújo, S. A. C.; Amorim, M. M.; Rodrigues, P. R. Sistema silvipastoril como alternativa de uso da terra. Pubvet, v. 5, n. 38, p. 1245 1250, 2011.

Bonini, C. S. B.; Lupatini, G. C.; Andrighetto, C.; Mateus, G. P.; Heinrichs, R.; Aranha, A. S.; Santana, E. A. R.; Meirelles, G. C. Produção de forragem e atributos químicos e físicos do solo em sistemas integrados de produção agropecuária. Pesquisa Agropecuária Brasileira, v. 51, n. 9, p. 1695-1698, 2016. https://doi.org/10.1590/s0100-

204x201600090007

Carvalho, W. T. V.; Minighin, D. C.; Gonçalves, L. C.; Villanova, D. F. Q.; Mauricio, R. M.; Pereira, R. V. G. Pastagens degradadas e técnicas de recuperação: Revisão. Pubvet, v. 11, n. 10, p. 1036-1045, 2017.

Diel, D.; Behling, M.; Farias Neto, A. L.; Isernhagen, E. C. C. Distribuição horizontal e vertical de fósforo em sistemas de cultivos exclusivos de soja e de integração lavourapecuária-floresta. Pesquisa Agropecuária Brasileira, v. 49, n. 8, p. 639-647, 2014. https://doi.org/10.1590/S0100-204X2014 000800008 
Jakelaitis, A.; Silva, A. A.; Ferreira, L. R.; Silva, A. F.; Freitas, F. C. L. Manejo de plantas daninhas no consórcio de milho com capimbraquiária (Brachiaria decumbens). Planta Daninha, v. 22, n. 4, p. 553-560, 2004. https://doi.org/10.1590/S010083582004000400009

Keller, L.; Leles, P. S. S.; Oliveira Neto, S. N.; Coutinho, R. P.; Nascimento, D. F. Sistema de blocos prensados para produção de mudas de três espécies arbóreas nativas. Revista Árvore, v. 33, n. 2, p. 305-314, 2009. https://doi.org/10.1590/S010067622009000200012

Moreira, G. R.; Saliba, E. O. S.; Maurício, R. M.; Sousa, L. F.; Figueiredo, M. P.; Gonçalves, L. C.; Rodriguez, N. M. Avaliação da Brachiaria brizantha cV. marandu em sistemas silvipastoris. Arquivo Brasileiro de Medicina Veterinária e Zootecnia, v. 61, n. 3, p. 706-713, 2009. https://doi.org/ 10.1590/S0102-09352009000300026

Nepomuceno, G. L. Formação de pastagem. Lavras: Universidade de Lavras, 2016. Disponível em: <https://3rlab.wordpress. com/2016/08/24/formacao-de-pastagem/>. Acesso em: 07 fev. 2019.

Nogueira, A. K. S.; Rodrigues, R. A. R.; Silva, J. J. N.; Botin, A. A.; Silveira, J. G.; Monbach, M. A.; Armacolo, N. M.; Romeiro, S. O. Fluxos de óxido nitroso em sistema de integração lavoura-pecuária-floresta. Pesquisa Agropecuária Brasileira, v. 51, n. 9, p. 11561162, 2016. https://doi.org/10.1590/s0100204x2016000900015

Oliveira, G. G.; Oliveira, G. C.; Silva, E. A.; Carducci, C. E.; Barbosa, S. M.; Silva, B. M. Indicadores de qualidade física para Argissolos sob pastagens na região leste e sul de Minas Gerais. Revista de Ciências Agrárias, v. 58, n. 4, p. 388-395, 2015.

Pinheiro, A. G.; Santos, J. C. N. S.; Palácio, H. A. Q.; Araújo Neto, J. R.; Andrade, E. M. Eficiência da cobertura vegetal na redução das perdas de água e solo no município de Iguatu. Irriga, v. 23, n. 1, p. 133-142, 2018. https://doi.org/ 10.15809/irriga.2018v23n1p133

Ralisch, R.; Miranda, T. M.; Okumura, R. S.; Barbosa, G. M. C.; Guimarães, M. F.; Scope, E.; Balbino, L. C. Resistência à penetração de um Latossolo Vermelho Amarelo do Cerrado sob diferentes sistemas de manejo. Revista Brasileira de Engenharia Agrícola e
Ambiental, v. 12, n. 4, p. 381-384, 2008. https://doi.org/10.1590/S141543662008000400008

Rangel, J. H. A.; Muniz, E. N.; Sá, J. L.; Sá, C. O. Implantação e manejo de Sistema Integração Lavoura/Pecuária/Floresta com Gliricidia sepium. Circular Técnica-Embrapa, v. 60, p.1-7, 2010. Disponível em: <https://www.embrapa.br/busca-depublicacoes/-/publicacao/878448/ implantacao-e-manejo-de-sistemaintegracao-lavourapecuariafloresta-comgliricidia-sepium>. Acesso em: 07 fev. 2019.

Reis, A.; Mendes, A. M. S.; Silva, A. F.; Oliveira, A. R.; Faria, C. M. B.; Terao, D.; Silva, D. J.; Batista, D. C.; Texeira, F. A.; Souza, F. F.; Resende, G. M.; Barbosa, G. S.; Alencar, J, A.; Anjos, J. B.; Castro, J. M. C.; Alves, J. C. S. F.; Damaceno, L. S.; Queiroz, M. A.; Calgaro, M.; Braga, M. B.; Barbosa, M. A. G.; Lima, M. A. C.; Lima, M. F.; Cota, N. D.; Correia. M. C.; Souza, R. N. C.; Dias, R. C. S.; Cunha, T. J. F. Sistema de produção de melancia. Petrolina: Embrapa Semiárido, 2010. Disponível em: $<$ https://sistemasdeproducao.cnptia.embrap a.br/FontesHTML/Melancia/SistemaProduca oMelancia/index.htm>. Acesso em: 24 jan. 2018.

Rheinheimer, D. S.; Santos, E. J. S.; Kaminski, J.; Bortoluzzi, E. C.; Gatiboni, L. C. Alterações de atributos do solo pela calagem superficial e incorporada a partir de pastagem natural. Revista Brasileira de Ciência do Solo, v. 24, n. 4, p. 797-805, 2000. https://doi.org/ $10.1590 /$ S0100-06832000000400012

Silva, A.; Santos, F. L. S.; Barretto, V. C. M.; Freitas, J. R.; Kluthcouski, J. Recuperação de pastagem degradada pelo consórcio de milho, Urochloa brizantha cv. marandu e guandu. Revista de Agricultura Neotropical, v. 5, n. 2, p.39-47, 2018. https://doi.org/ 10.32404/rean.v5i2.1382

Silva, R. R.; Silva, P. G.; Lins, T. O. J. D.; Rodrigues, L. B. O. Novos sistemas de produção de bovinos de corte em pastejo: maximizando a produção com baixo impacto ambiental. Revista Científica de Produção Animal, v. 19, n. 1, p. 43-52, 2017.

Souza, F. F. Cultivo da melancia em Rondônia. Porto Velho: Embrapa Rondônia, 2008.

Tomaz, G. A.; Borges, A. S.; Wander, A. E.; Souza, C. B. Como viabilizar a adoção do 
sistema ILPF. Revista Sodebras, v. 12, n. 144, p. 55-60, 2017.

USDA - United States Department of Agriculture. Livestock and poultry: World markets and trade. United States Department of Agriculture, Foreign Agriculture Service, 2018. Disponível em: <https://apps.fas.usda. gov/psdonline/circulars/livestock_poultry.p df>. Acesso em: 07 fev. 2019.

Vilela, L.; Martha Junior, G. B.; Macedo, M. C. M.; Marchão, R. L.; Guimarães Junior, R.; Pulrolnik, K.; Maciel, G. A. Sistemas de integração lavoura-pecuária na Região do Cerrado. Pesquisa Agropecuária Brasileira, v. 46, n. 10, p. 1127-1138, 2011. https://doi.org/10.1590/S0100-

204X2011001000003
Vilela, L.; Soares, W. V.; Sousa, D. M. G.; Macedo, M. C. M. Calagem e adubação para pastagens na região do cerrado. Planaltina: EMBRAPA/CPAC, 1998. (Circular Técnica, 37). Disponível em: <https://www.infoteca. cnptia.embrapa.br/infoteca/bitstream/doc/3 21682/1/cirtec37.pdf>. Acesso em: 07 fev. 2019.

Yuri, J. E.; Costa, N. D.; Pinto, J. M.; Correia, R. C. Cultivo da melancia no Vale do São Francisco. Petrolina: Embrapa Semiárido, 2013. (Instruções técnicas da Embrapa Semiárido, 113). Disponível em: <https://www.infoteca.cnptia.embrapa.br/in foteca/bitstream/doc/981668/1/INT113.pdf >. Acesso em: 07 fev. 2019 